Research Article

\title{
Thrust Ripple Force Minimization and Efficiency Analysis of Electromagnetic Actuator on Active Suspension
}

\author{
Kou Farong $\mathbb{D}^{\mathbb{D}}$, Li Yangkang $\mathbb{D}$, Chen Chen, and Hong Feng \\ School of Mechanical Engineering, Xi'an University of Science and Technology, Xi'an 710054, China \\ Correspondence should be addressed to Li Yangkang; lykeducation096@163.com
}

Received 6 August 2019; Revised 24 October 2019; Accepted 20 November 2019; Published 10 March 2020

Academic Editor: Mohammad Rafiee

Copyright (C) 2020 Kou Farong et al. This is an open access article distributed under the Creative Commons Attribution License, which permits unrestricted use, distribution, and reproduction in any medium, provided the original work is properly cited.

\begin{abstract}
A novel electromagnetic actuator for active suspension is designed on an in-wheel motor electric vehicle in this paper. Aiming at reducing thrust ripple force and improving stability of the actuator, a method of calculating the optimum slot width and optimizing edge radian of end tooth is proposed. Firstly, a finite element model (FEM) of the actuator is modeled, and the correctness of FEM is verified through comparisons of simulation results and analytical ones, including counterelectromotive force of coil winding and force characteristic test of the actuator. Based on the FEM, the influence of slot width on electromagnetic thrust and total harmonic distortion (THD) is analyzed, and the slot width is improved. The side effect of the actuator is considered. By improving the edge radian, the fluctuation of the cogging force and thrust ripple is reduced. In addition, output efficiency and energy feed efficiency of the actuator after reducing thrust ripple are studied. The results show the minimum THD is $4.2 \%$, which is obtained at the slot width $4.3 \mathrm{~mm}$, and thrust ripple is $36.5 \mathrm{~N}$. When the edge radian is $60^{\circ}$, the thrust ripple decreases to only $15.7 \mathrm{~N}$, which is reduced by $57.0 \%$. The maximum output efficiency and energy feedback efficiency of the actuator are $87.5 \%$ and $27.1 \%$, respectively. Finally, according to actuator characteristic tests of two working modes, it is concluded that the maximum energy feedback efficiency is $25.6 \%$. The input current and current frequency should be gradually increased with the increase of suspension speed under active mode, and the maximum output efficiency is $80.2 \%$. The test results are basically consistent with the FEM analysis values, which verify the correctness of the FEM analysis.
\end{abstract}

\section{Introduction}

In-wheel motor has become a new development direction on an electric car because of reducing chassis space, short transmission chain, and high efficiency. However, the riding comfort and stability of the vehicle are deteriorated due to the increase of unsprung mass [1-3]. The traditional suspension is composed of spiral spring and hydraulic shock absorber. Its stiffness and damping coefficients cannot be changed with the road irregularity and driving condition, so further improvement performance is limited [4-7]. An active suspension system can meet the requirement of operational stability and driving safety by controlling [8-11] and has gradually become a more and more significant research field. As one of the core components of active suspension, the actuator has an important impact on the overall performance of active suspension. With the rapid development of linear motor technology and its distinctive advantages of fast response, high efficiency, and small inertia, many scholars have studied the electromagnetic actuator on active suspension [12-14].

Some scholars study the electromagnetic actuators and use rotating motors to convert rotating motion into linear motion through intermediate transmission devices, such as ball screw or gear rack $[9,15-18]$, but the component mechanism is complex and transmission efficiency is low. In the process of high vibration frequency, the response ability of the actuator becomes bad because of inherent inertia in the rotating motor. In [19-21], an electromagnetic linear actuator designed by the principle of electromagnetic induction is simple in structure and does not need intermediate transmission devices, but it has some shortcomings such as low density of air gap magnetic field, large occupation space, and excessive heating, which cannot be used in 
the working status for a long time. In [22], the study aims at the problem that thrust harmonic of linear motor will reduce the motion stability, a method of changing the ratio of slot opening and slot distance is proposed, and the result shows that this parameter has an important influence on the main harmonic order and amplitude of thrust ripple force, but it lacks theoretical analysis on the specific slot opening size. In [23], Yu studies relevant parameters about power of linear motor, and the result indicates that the power and working efficiency of linear motor can be improved by adjusting the length of secondary magnetization direction and phase angle of armature current and reducing thickness of stator tooth top. In [24], Klimenko et al. design a linear electromagnetic actuator with an active suspension system. For the proposed design, formulas that determine the geometric parameters are selected for the armature form, dimensions of the air gap, motor step, and winding parameters. On this basis, selection and determination of the geometric dimensions of the module elements are determined operating under quasioptimal ratios of basic dimensions in the magnetic core. However, there is no analysis of working characteristic after the design, which cannot guarantee performance of the actuator. In [25], an improved permanent magnet synchronous linear motors structure with arc-teeth and innerladder end teeth is proposed in this study to reduce detent force. This structure reduces detent force and keeps motor size constant, but the influence of cogging force on fluctuation force is neglected.

In this paper, a novel electromagnetic actuator on active suspension is designed on an in-wheel motor electric vehicle. Under the premise meeting requirement of damping vibration performance and improving stability of the actuator, the energy of suspension vibration could be recovered. A novel electromagnetic actuator for active suspension is designed on an in-wheel motor electric vehicle in Section 2. In Section 3, the finite element model (FEM) is modeled, which verified the correctness by theoretical calculation of counter electromotive force (CEMF) and force characteristic test of the actuator. In Section 4, considering the influences of cogging force and end force on thrust ripple force, the optimal slot width and edge radian of end tooth are obtained by combining theoretical calculation with FEM simulation. In Section 5, in order to check the performance of the actuator after thrust ripple force minimization, the output efficiency and energy feedback efficiency under two modes are, respectively, analyzed. In Section 6, according to structure design parameters, the prototype of actuator is improved and two working mode tests are carried out to obtain its working characteristic and energy feedback efficiency, which verifies the correctness of the efficiency of finite element analysis and provides a reference for whole vehicle equipment of the actuator.

\section{Principle and Structure Design of the Electromagnetic Actuator}

2.1. Principle of the Electromagnetic Actuator. A schematic diagram of an electromagnetic actuator on an in-wheel motor is shown in Figure 1. The electromagnetic active

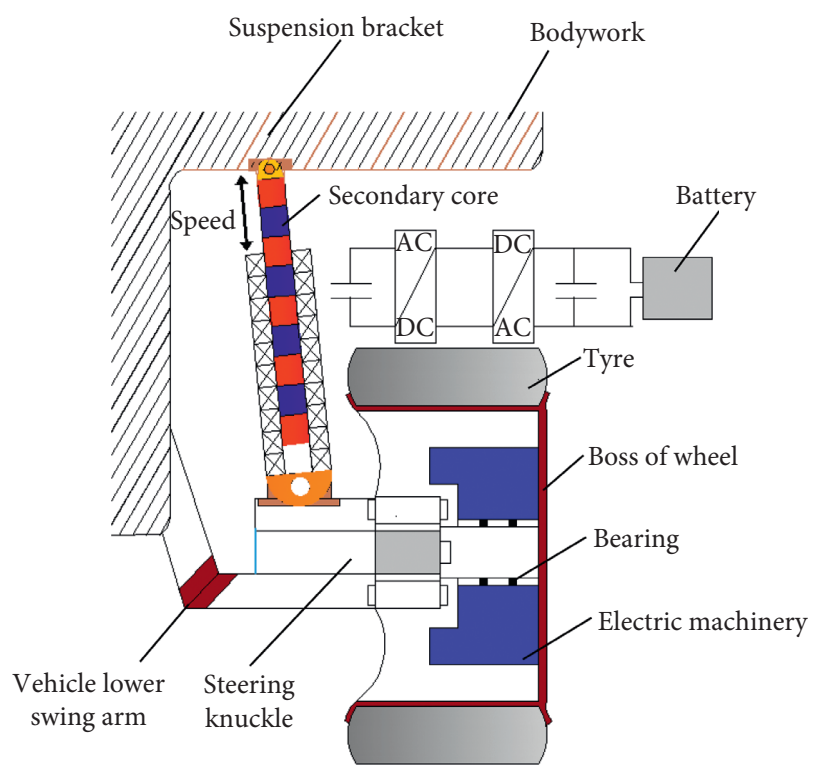

FIGURE 1: Schematic diagram of electromagnetic actuator on an inwheel motor.

suspension system includes primary core and secondary core and electromagnetic suspension bracket. The secondary core of the actuator is hardwired to the bodywork through the suspension bracket, and the primary core of the actuator is connected to the unsprung mass through the fixator. The actuator adopts the design of outer primary winding and inner secondary permanent magnet. The secondary core moves inside the primary core in linear motion. In the limited space, it cannot only make the secondary winding contact fully with the permanent magnet field and maximize the performance of the actuator but also realize the secondary core's up and down moving directions, increasing the suspension travel. There are two working modes of the actuator: when the actuator is under active mode, the current of the winding coil is controlled by the peripheral circuit to generate active electromagnetic force. The electromagnetic thrust can directly suppress the upper and lower vibration of the bodywork, which meets the reduction vibration demand of high speed and large vibration of the vehicle. When the actuator is under the energy feedback mode, the small amplitude of the bodywork directly drives the up and down movement of the actuator. The three-phase coil cuts magnetic induction line and generates the induced current. The induced current is filtered, rectified, and inverted to charge the battery, so the energy recovery is realized. The designed electromagnetic actuator not only has the functions of active electromagnetic thrust and passive energy feeding but also has the advantages of small volume, large stroke, and high efficiency.

2.2. Structure Design of the Electromagnetic Actuator. In order to meet the demand of reduction vibration performance and small equipment space, the following requirements are proposed for the shape and size of the actuator. The primary outer diameter of the electromagnetic actuator 
is less than $85 \mathrm{~mm}$. The primary length of the actuator is less than $300 \mathrm{~mm}$. The secondary length is not less than $500 \mathrm{~mm}$, and it adopts radial magnetization. The air gap length is $1 \mathrm{~mm}$. For simplifying equipment of the primary and winding core, the ratio of primary outer diameter and secondary outer diameter is selected as $2: 1$ [26]. We choose the number of slots is 12 and its structure is flat bottom. The slot width is equal to $12 \mathrm{~mm}$. Matching of actuator slots and poles is shown in Table 1.

Table 1 shows that integer slots are larger than fractional slots obviously when pole logarithms are the same. In order to reduce volume of the actuator, the structure of fractional slots is selected in this paper. When the fractional slots are 12 , the pole logarithms are 4,5 , or 7 . According to the formula in [27] $2 p=N \pm 2, N$ and $P$ represent slots and pole logarithms, respectively. When the pole logarithms are equal to 5 or 7 , harmonic electromotive force of different orders in winding and fluctuation force are reduced. In [28], the study illustrates that the more pole logarithms have, the more magnetic leakage it will produce. At the same speed, the electromagnetic loss of iron and driver switch is greater, so it will reduce service life of the actuator. Therefore, the structure adopts 12 slots and 10 poles on the actuator, and the specific size is shown in Table 2 .

\section{FEM of the Actuator}

3.1. Modeling of the Actuator FEM. According to the main structural parameters of the actuator in Table 2, a two-dimensional FEM is modeled, and each part of material is defined and assigned in the model. The coil winding is defined as copper wire, the diameter is $1 \mathrm{~mm}$, the primary and secondary iron cores are made of DW465-50 rolled by silicon steel sheets, the permanent magnet is $\mathrm{N} 30 \mathrm{NdFeB}$, its coercivity is $838 \mathrm{KA} / \mathrm{m}$, and residual flux density is $1.1 \mathrm{~T}$. Before actuator analysis, the balloon boundary is applied outside the moving area of the actuator. Because the electromagnetic actuator is symmetrical, one-half FEM is established along the $Z$-axis. The model is shown in Figure 2.

In order to get accurate FEM simulation result of the actuator, we need to mesh the solution part closely. The mesh length of actuator surface is equal to $2 \mathrm{~mm}$. The primary coil is divided into $2.5 \mathrm{~mm}$. The length of secondary core is set to $3 \mathrm{~mm}$, and the mesh length of the permanent magnet is $0.2 \mathrm{~mm}$. Figure 3 shows the result of the meshing model.

\subsection{Verifying the Actuator Model}

3.2.1. Calculation of the CEMF. CEMF is an important parameter of the actuator. Its amplitude and sinusoidal degree directly affect the wave force. In this paper, theoretical calculation and finite element simulation analysis are compared to verify the correctness of the model. Figure 4 shows a schematic diagram of the actuator mechanism size.

The primary slot of the actuator is an open structure, so the carter coefficient is introduced as
TABLE 1: Matching of actuator slots and poles.

\begin{tabular}{|c|c|c|}
\hline \multicolumn{2}{|c|}{ Slots } & \multirow{2}{*}{ Pole logarithms } \\
\hline Fractional slots & Integer slots & \\
\hline $6,9,12$ & 24 & 4 \\
\hline $9,12,15$ & 30 & 5 \\
\hline $12,15,21$ & 42 & 7 \\
\hline
\end{tabular}

TABLE 2: Main structural parameters of the actuator.

\begin{tabular}{lc}
\hline Parameters & Length $(\mathrm{mm})$ \\
\hline Primary & 380 \\
Secondary & 540 \\
Primary outer diameter & 80 \\
Secondary outer diameter & 40 \\
Tooth height & 20 \\
Slot width & 12 \\
Tooth space & 11 \\
Air gap & 1 \\
Permanent magnet height & 3.5 \\
Permanent magnet width & 13 \\
\hline
\end{tabular}

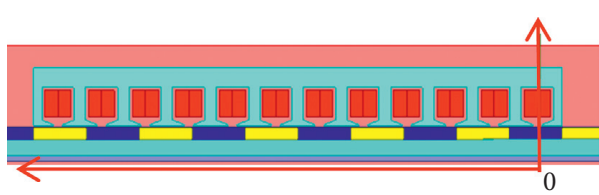

FIgURE 2: Finite element model.

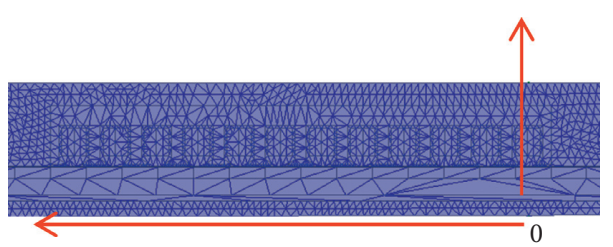

Figure 3: Mesh dividing model.

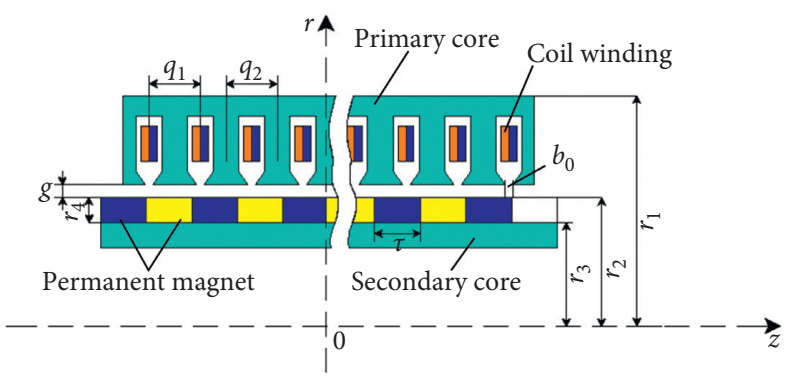

FIgURE 4: Structural dimension diagram of actuator. $b_{0}$ : notch width; $g$ : air gap; $q_{1}$ : actuator coil distance; $q_{2}$ : tooth distance; $\tau$ : pole distance length of permanent magnet; $r_{1}$ : primary external diameter; $r_{2}$ : secondary external diameter; $r_{3}$ : radius of secondary core; $r_{4}$ : permanent magnet width.

$$
K_{c}=\frac{q_{2}^{2}}{q_{2}^{2}-r g^{\prime}}
$$


where $g^{\prime}=g+\left(r_{4} / u\right), u$ is the permanent magnet conductivity, $u=1.1, r$ is the slot coefficient:

$$
r=\frac{4}{\pi}\left[\frac{b_{0}}{2 g^{\prime}} \tan ^{-1}\left(\frac{b_{0}}{2 g^{\prime}}\right)-\ln \sqrt{1+\left(\frac{b_{0}}{2 g^{\prime}}\right)^{2}}\right]
$$

The effective air gap is obtained as

$$
g_{1}=g+\left(K_{C}-1\right) g^{\prime}
$$

The effective armature thickness is simplified as

$$
h_{t}=r_{2}+g_{1} \text {. }
$$

The $(2 n-1)$ subharmonic coefficient is calculated as

$$
K_{r n}=h_{t}\left[a_{I n} B I_{1}\left(f_{n} h_{t}\right)+b_{I n} B K_{1}\left(f_{n} h_{t}\right)\right] \text {, }
$$

where $f_{n}$ is the space frequency of harmonic wave, $f_{n}=(2 n-1) / \tau$, and $a_{\text {In }}$ and $b_{\text {In }}$ represent the first Bessel Function $B I_{1}(\cdot)$ coefficient and second Bessel Function $B K_{1}(\cdot)$ coefficient, respectively $[29,30]$.

The CEMF of the single-phase winding is described as

$$
\begin{aligned}
E_{p w} & =-v \sum_{n=1,2,3 \cdots}^{\infty} K_{E n} \sin f_{n}\left(z-\frac{q_{1}}{2}\right), \\
K_{E n} & =4 \pi p N_{c} K_{d p n} K_{r n}, \\
K_{d p n} & =K_{d n} K_{p n}, \\
K_{d n} & =\frac{\sin 0.5 f_{n} b_{0}}{0.5 f_{n} b_{0}} .
\end{aligned}
$$

where $v$ represents the operating speed of the actuator, $z=v t, z$ is the operating distance of the actuator, $N_{C}$ is the turn number winding of each pole, $K_{d p n}$ is the winding coefficient, $K_{d n}$ is the distribution coefficient, $K_{p n}$ represents the short distance coefficient, and $K_{p n}=1$.

The secondary moving speed of the actuator is set at $1.3 \mathrm{~m} / \mathrm{s}$. The variation of CEMF with time under no-load condition is analyzed and compared with theoretical calculation value. The result is shown in Figure 5.

Figure 5 shows that the theoretical calculation value of a periodic CEMF agrees well with the FEM simulation value under no-load condition, and it fluctuates sinusoidally with time. When the time of the secondary motion is $2.1 \mathrm{~ms}$, the theoretical calculation value of CEMF is the biggest difference with the finite element simulation value, the theoretical calculation value is $57 \mathrm{~V}$, and the finite element simulation value is $51 \mathrm{~V}$. The difference between them is about $10.5 \%$. This is due to neglecting the primary and secondary magnetic leakage phenomena mainly in the theoretical calculation.

3.2.2. Force Characteristic Test of the Actuator. The static electromagnetic force response test of the actuator is executed to further verify the correctness of the FEM. The test equipment consists of electromagnetic actuator prototype, horizontal fixed platform, TSVC2-6KGA three-phase

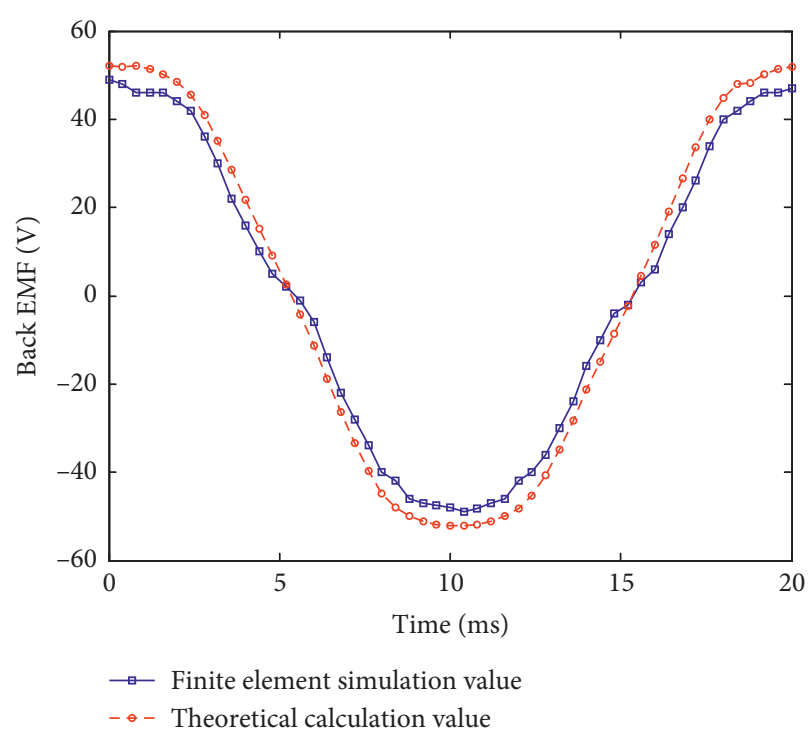

FIGURE 5: CEMF of single-phase coil winding.

voltage regulator, force sensor, data acquisition instrument, and $24 \mathrm{~V}$ power supply box, respectively. In order to eliminate self-weight influence of the actuator on output force, the prototype is horizontally installed on the fixing table and the force sensor is fixed to the secondary core through threaded hole. At the same time, data line of the force sensor is connected with the data acquisition instrument, and input voltage is controlled by the knob of the three-phase voltage regulator. Finally, the data acquisition instrument converts the collected force signal into digital signal and transmits the digital signal to host the computer for recording. The experiment is shown in Figure 6. During the test, the three-phase voltage regulator knob is adjusted to load different voltages on the electromagnetic actuator. The corresponding output force is measured by the force sensor and compared with the finite element simulation value. The result is shown in Figure 7.

Figure 7 shows that the test result and finite element simulation value of the average electromagnetic force are basically same, and the variation presents a linear distribution with time. When the input voltage of the actuator is $20 \mathrm{~V}$, the difference between them is the greatest. At this time, the average electromagnetic force test value is $331 \mathrm{~N}$ and the finite element simulation value is $350 \mathrm{~N}$. The error between them is $5.4 \%$. The main reason is that finite element simulation simplifies the actuator as an ideal model, without considering the loss of mechanical energy, iron loss, copper loss, and other energy. Finally, the correctness of the FEM of the electromagnetic actuator is verified by the comparative analysis of the CEMF and the force characteristic test.

\section{Reduction of Thrust Ripple Force}

4.1. Analysis of Slot Width. The slot width of the actuator has a great influence on the electromagnetic thrust force and fluctuation force because it determines the teeth pole boot width of the primary core. Through comparing theoretical calculation with finite element simulation result, the optimal 


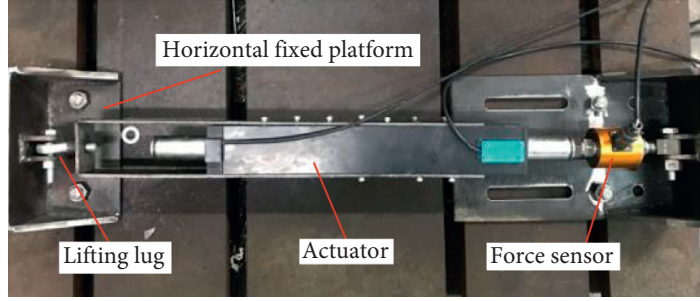

(a)

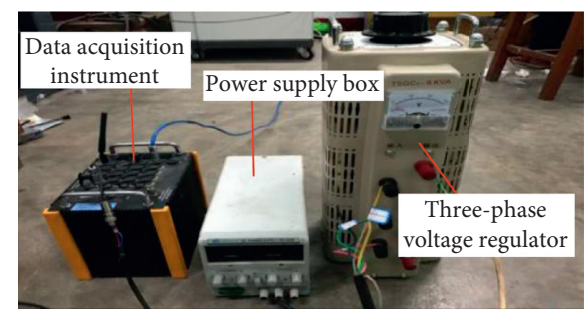

(b)

Figure 6: Force characteristic test of the actuator.

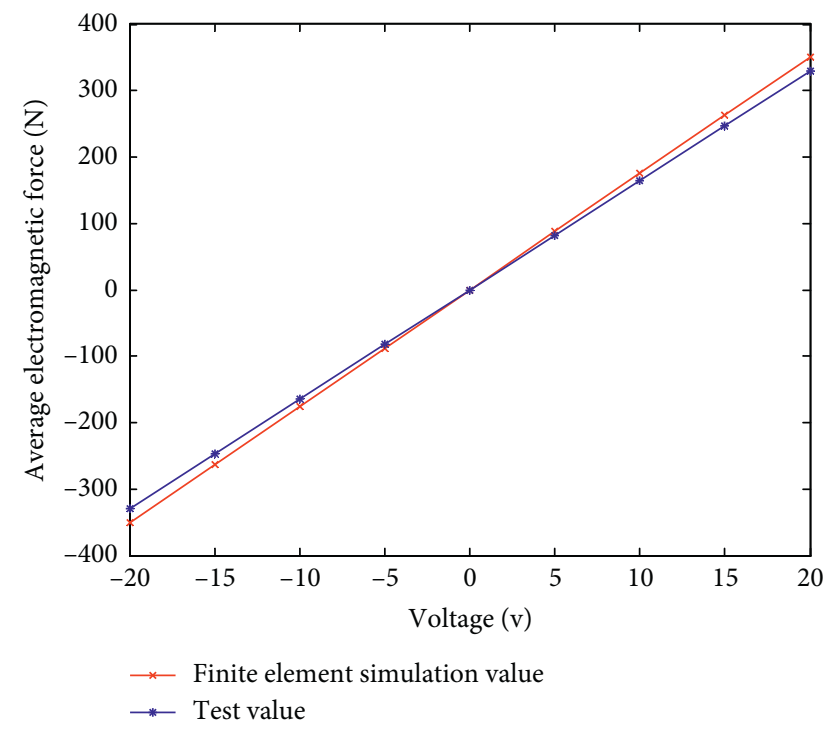

Figure 7: Variation of average electromagnetic force with voltage.

slot width is obtained, which can reduce the slot effect influence and improve the working accuracy of the electromagnetic actuator. To simplify calculation, the following assumptions are made: (a) The eddy current loss of the actuator core is neglected. (b) The shape of the primary teeth is rectangular. (c) The air gap magnetic field between primary and secondary is square wave. (d) Permanent magnet has the same magnetic permeability as air.

Ignoring the saturation of the core, the total magnetic field energy $w$ of the actuator can be approximately equal to the energy $w_{\text {gap }}$ of the gap magnetic field, and the cogging force is simplified as [31]

$$
\begin{aligned}
F_{\text {th }} & =-\frac{\partial W}{\partial \alpha} \cdot \frac{1}{r_{1}} \approx-\frac{\partial W_{\text {gap }}}{\partial \alpha} \cdot \frac{1}{r_{1}}, \\
W_{\text {gap }} & =\frac{1}{2 u_{0}} \iiint_{v} B(\theta, \alpha)^{2} \mathrm{~d} V \\
& =\frac{L\left(r_{1}^{2}-r_{2}^{2}\right)}{4 u_{0}} \int_{0}^{2 \pi} B_{r}^{2}(\theta)\left[\frac{h(\theta)}{h(\theta)+\delta(\theta, \alpha)}\right]^{2} \mathrm{~d} \theta,
\end{aligned}
$$

where $B(\theta, \alpha)$ is the air gap magnetic density, $B_{r}(\theta)$ is the distribution function of remaining magnetism along the axis, $L$ is the length of the armature core, $r_{1}$ is the primary cylindrical radius, $r_{2}$ is the secondary cylindrical radius, $\delta(\theta, \alpha)$ is the air gap length, $h(\theta)$ is the radial distribution function of permanent magnet, and $u_{0}$ is the air permeability:

$$
\begin{aligned}
N & =\frac{2 P}{G C D(Z, 2 P)}, \\
n & =k \frac{2 P}{G C D(Z, 2 P)}=K N, \quad k=1,2,3, \ldots,
\end{aligned}
$$

where $p$ is the polar logarithm of electromagnetic actuator, $z$ is the number of slots in the actuator, and GCD is the greatest common divisor:

$$
F_{\text {th }}=\frac{\pi Z L}{4 r_{1} u}\left(r_{1}^{2}-r_{2}^{2}\right) \sum_{k=1}^{\infty} k N G_{k} B_{r} \sin k N Z \alpha
$$

where $G_{k}$ is the Fourier decomposition coefficient of relative air gap permeability square and $B_{r}$ is the Fourier decomposition coefficient of air gap density square generated by permanent magnet [32]:

$$
G_{K}=\frac{2}{N \pi}\left(\frac{h_{m}}{h_{m}+\delta}\right)^{2} \sin N\left(\pi-\frac{Z b_{0}}{2}\right) .
$$

In order to achieve the effect of reducing cogging force, choosing slot width $b_{0}$ is to make $G_{k}$ as closely to zero as possible:

$$
\begin{aligned}
\sin N\left(\pi-\frac{Z b_{0}}{2}\right) & =0 \\
b_{0} & =\left(1-\frac{i}{N}\right) \cdot \frac{2 \pi}{Z}, \quad(0<i<N, i \text { is integer }) .
\end{aligned}
$$

Thus, $i$ can take values $1,2,3$, and 4 , and $b_{0}$ is $4.2 \mathrm{~mm}$, $3.1 \mathrm{~mm}, 2.1 \mathrm{~mm}$, and $1.0 \mathrm{~mm}$, respectively. According to the results of theoretical calculation, the load voltage of the actuator is $25 \mathrm{~V}$ and the secondary operating speed is $0.13 \mathrm{~m} /$ $\mathrm{s}$. The average electromagnetic force and the fluctuation ratio of the actuator are analyzed with the different slot widths under load condition, and the result is shown in Figure 8.

Figure 8 shows that when the slot width increases, average electromagnetic force of the actuator decreases due to the increase of magnetic leakage in the air gap. The slot width is equal to $4.3 \mathrm{~mm}$, the average electromagnetic force of the actuator is $384.3 \mathrm{~N}$, the minimum fluctuation ratio of the actuator is $9.5 \%$, and the minimum thrust ripple force is $36.5 \mathrm{~N}$. The slot width is similar to the result obtained by 


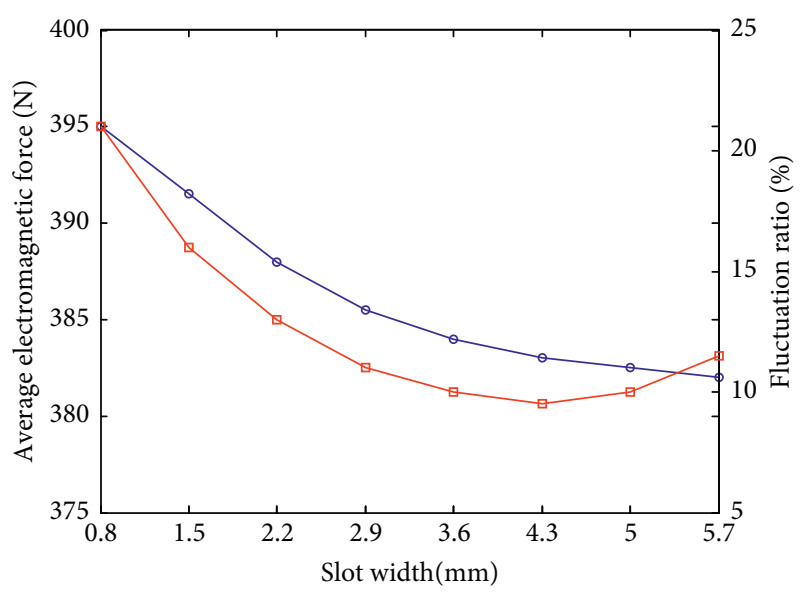

$\rightarrow$ Average electromagnetic force $(\mathrm{N})$

$\square$ Fluctuation ratio

FIGURE 8: Changes of average electromagnetic force and fluctuation ratio with slot width.

theoretical calculation, but there is still difference. The main reason is that the result obtained by the calculation method neglects eddy current and hysteresis loss and assumes the air gap magnetic field as square wave, which is different from the actual operation state of the actuator. At the same time, the stability of the actuator is improved obviously with the small sacrifice of average electromagnetic force.

In order to further analyze the effect of slot width on thrust ripple force, we study the induced electromotive force of the actuator. The induced electromotive force of coil winding is not completely sinusoidal in practical work of the actuator. It contains some harmonic components and generates thrust ripple force under the action of induced current. Because the loaded current is an ideal sinusoidal wave, this paper analyzes the harmonic of induced electromotive force. The ratio of harmonic and fundamental components is to evaluate harmonic component; the calculation formula is as follows:

$$
\eta=\frac{G_{n}}{G_{1}}
$$

where $\eta$ is the ratio of harmonic and fundamental, $G_{n}$ is the effective value of the $n$th time harmonic component, and $G_{1}$ is effective value of fundamental component.

Figure 9 shows the harmonic component of induced electromotive force. It can be seen that except the fundamental component of induced electromotive force, the harmonic mainly exists in the 3rd, 2nd, 4th, 5th, and 6th time. Among them, the $3 \mathrm{rd}$ harmonic component accounts for the largest proportion of fundamental and the 6th time harmonic accounts for the smallest proportion of fundamental component. So $n$ is equal to 6 in formula (9).

The harmonic distortion rate is used to evaluate the waveform influence of induced electromotive force under different slot widths. The calculation process is as follows:

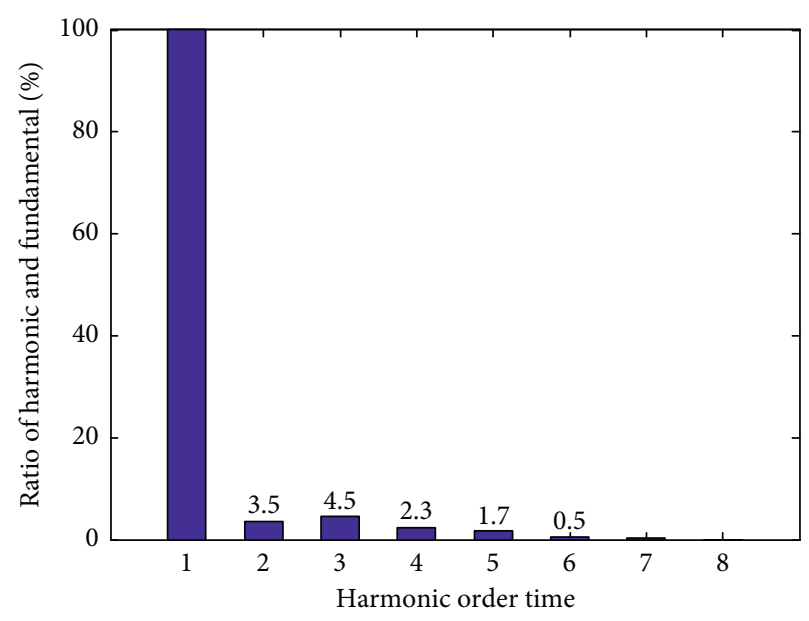

FIGURE 9: Harmonic component of the induced electromotive force.

$$
R_{\mathrm{THD}}=\sqrt{\sum_{N=2}^{H}\left(\frac{G_{n}}{G_{1}}\right)^{2}},
$$

where $R_{\mathrm{THD}}$ is the total harmonic distortion rate and $H=5$.

According to the result of theoretical calculation of slot width, we change the slot width and get different total harmonic distortion rates. The result is shown in Figure 10.

Figure 10 shows that the total harmonic distortion rate decreases and then increases with the increase of slot width. When slot width is $4.3 \mathrm{~mm}$, the total harmonic distortion rate is the minimum, which is similar to the theoretical calculation result. Therefore, when the slot width is $4.3 \mathrm{~mm}$, the cogging force can be effectively reduced and the stability of actuator can be improved.

4.2. Analysis of Edge Radian of End Tooth. The generation of end effect on the actuator is caused by the sudden change of edge magnetic field, and choosing appropriate primary length can effectively reduce the thrust ripple force. Besides, the coupling theory of smooth edge shape of the end tooth and magnetic field of the sinusoidal air gap can be selected to reduce the end force of the actuator. The edge radian of end tooth on the actuator is shown in Figure 11.

In this paper, simulation time of the actuator is $300 \mathrm{~ms}$ and the secondary speed is set to $0.13 \mathrm{~m} / \mathrm{s}$. The cogging force is analyzed under no-load condition by changing edge ra$\operatorname{dian} \theta$ of end tooth. The result is shown in Figure 12.

Figure 12 shows when the edge radian of end tooth on the actuator is equal to $60^{\circ}$, the fluctuation of the cogging force is the smallest. Compared with the original model, the fluctuation force range is decreased from $21.4 \mathrm{~N}$ to $9.5 \mathrm{~N}$.

In order to further analyze the change of the electromagnetic force on the actuator, the current of $3.5 \mathrm{~A}$ is loaded on the actuator and the secondary speed is set to $0.13 \mathrm{~m} / \mathrm{s}$. The variation of the electromagnetic force with time is 


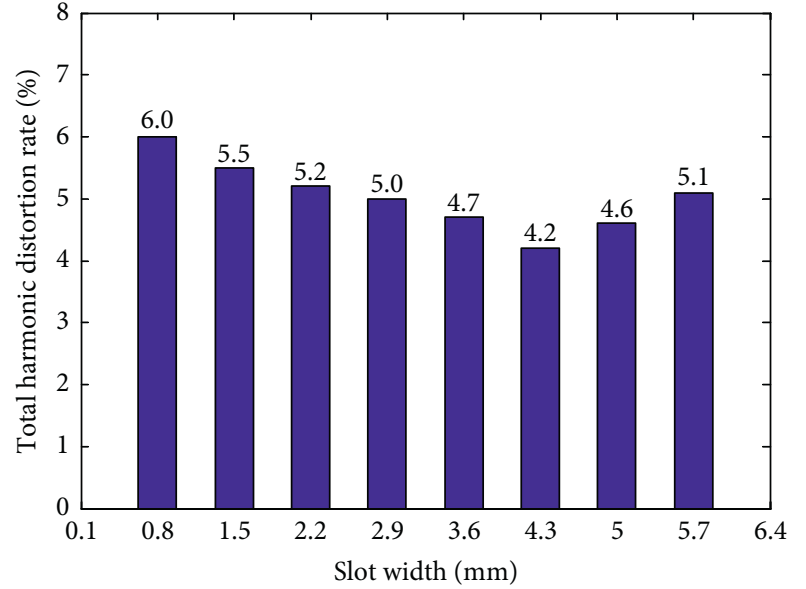

Figure 10: Changes of total harmonic distortion rate with slot width.

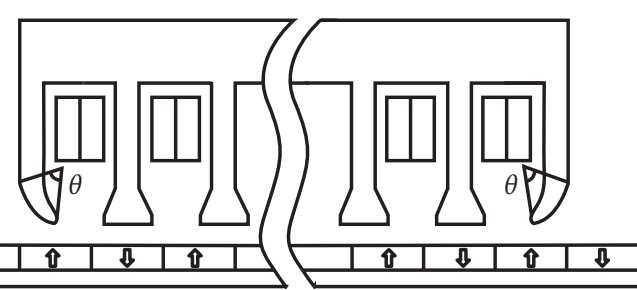

FIGURE 11: Edge radian of end tooth on the actuator.

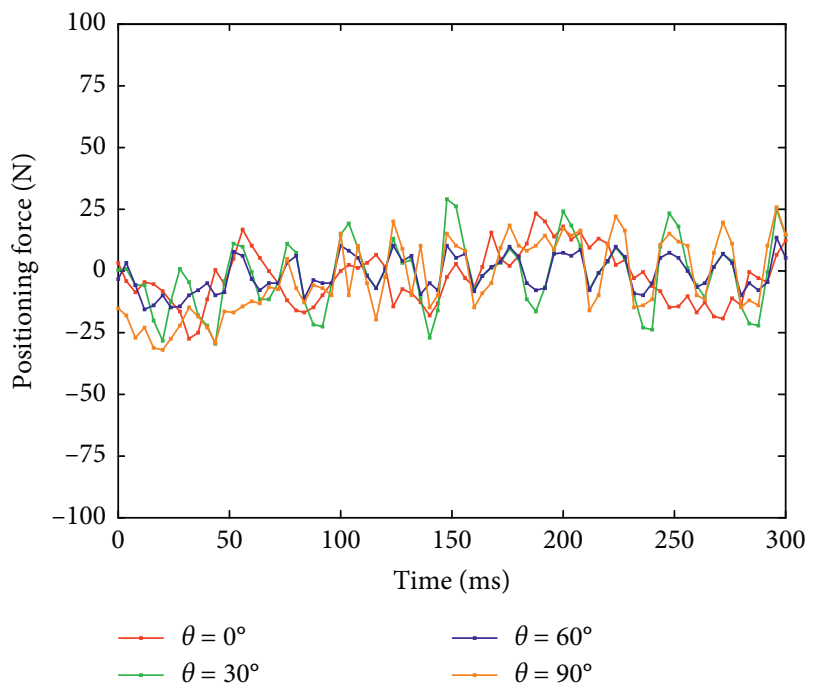

FIGURE 12: Cogging force at different edge radians.

analyzed, as shown in Figure 13. The changes of fluctuation force are also calculated, and the result is shown in Table 3.

Figure 13 and Table 3 show that the electromagnetic fluctuation force is equal to $36.5 \mathrm{~N}$ before improvement of edge radian under load condition, and the fluctuation force is reduced by $20.8 \mathrm{~N}$ with the change ratio of $57.0 \%$ by improving edge radian. The cogging force of the actuator under no-load condition decreases from $21.4 \mathrm{~N}$ to $9.5 \mathrm{~N}$, and

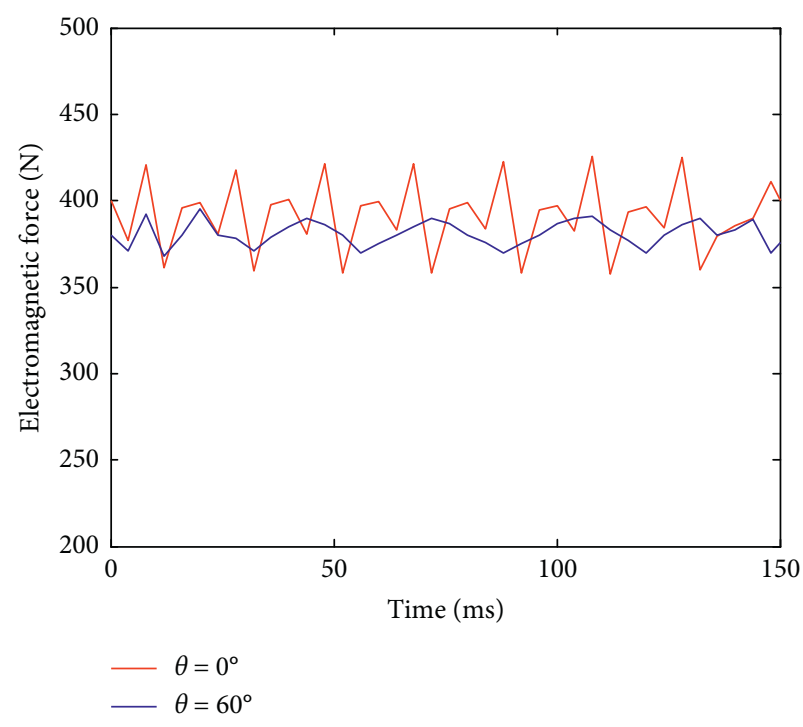

Figure 13: Electromagnetic force varies with time.

the change ratio is $55.6 \%$. Therefore, the cogging fluctuation force and electromagnetic fluctuation force are reduced significantly. In addition, the cogging fluctuation force of the actuator accounts for 60.5 percent on the electromagnetic fluctuation force, and it can be concluded that the cogging force is the main source of thrust ripple force.

\section{Efficiency of the Actuator}

5.1. Output Efficiency of the Actuator under Active Mode. The output efficiency is an important index to measure the output capability and stability of the electromagnetic actuator. On the basis of structural design, ignoring the loss of mechanical energy, the energy consumption of actuator mainly includes effective power and heat loss of coil winding. This paper calculates the load of voltage and current on the actuator as input power, and electromagnetic thrust force and operating speed of the actuator are calculated as output power. Due to the fluctuation of electromagnetic force, this paper uses the average electromagnetic thrust force as the effective calculation value. The formula for calculating the output efficiency of the actuator is expressed as [33]

$$
\begin{aligned}
\eta_{t} & =\frac{W_{e}}{W_{i}} \times 100 \%, \\
P_{e} & =\left|F_{e} V_{e}\right|=\left|2 F_{e} \tau \cdot f\right|, \\
W_{e} & =\int_{0}^{T_{1}}\left|2 F_{e} \tau \cdot f\right| \mathrm{d}_{t}, \\
P_{i} & =U_{i} I_{i}, \\
W_{i} & =\int_{0}^{T_{1}} U_{i} I_{i} d_{t},
\end{aligned}
$$

where $\eta_{t}$ is the output efficiency, $W_{e}$ is the output energy, $W_{i}$ is the input energy, $P_{e}$ is the output power, $P_{i}$ is the input power, $F_{e}$ is the average electromagnetic thrust force, $V_{e}$ is 
TABLE 3: Changes of fluctuation force.

\begin{tabular}{lcc}
\hline & Cogging fluctuation force $(\mathrm{N})$ & Electromagnetic fluctuation force $(\mathrm{N})$ \\
\hline Before improvement of edge radian & 21.4 & 36.5 \\
After improvement of edge shape & 9.5 & 15.7 \\
Change value & $11.9(55.6 \%)$ & $20.8(57.0 \%)$ \\
\hline
\end{tabular}

the moving speed of actuator, $\tau$ is the pole distance length of permanent magnet, $f$ is the frequency of three-phase current, $U_{i}$ is the input voltage, and $I_{i}$ is the input current.

The variation of the average electromagnetic thrust force and output efficiency of the actuator with current frequency under different input currents is simulated and analyzed, as shown in Figure 14.

Figure 14 shows that the average electromagnetic thrust force of the actuator increases with the increase of input current and decreases with the increase of current frequency. The minimum value of the actuator thrust force at low input current and high current frequency is $16.8 \mathrm{~N}$, and the maximum value at high input current and low current frequency is $659.3 \mathrm{~N}$. The output efficiency decreases with the increase of input current and increases with the increase of current frequency. The lowest efficiency is $7.1 \%$ at high input current and low current frequency, and the highest output efficiency is $87.5 \%$ at low input current and high current frequency.

\subsection{Energy Recovery Efficiency of the Actuator under Energy} Feedback Mode. When the electromagnetic suspension system is under energy feedback mode, the excitation of road irregularity drives the relative motion between the primary and secondary cores of the actuator. The three-phase coil cuts the magnetic induction line and generates induced current. The induction current in winding can be charged to the battery by filtering, rectifying, and inverting, so as to recover energy and realize energy recycling. In this paper, the energy feed circuit of the actuator is constructed, and we can obtain energy feedback voltage and current under different moving speed and load conditions. The total input power of the actuator can be obtained by the electromagnetic damping coefficient and the speed of moving. The energy feed efficiency calculation formula is obtained as follows:

$$
\begin{gathered}
\eta_{f}=\frac{W_{c}}{W_{g}} \times 100 \%, \\
P_{c}=\left|U_{c} I_{c}\right|, \\
W_{c}=\int_{0}^{T_{2}}\left|U_{C} I_{C}\right| d_{t}, \\
P_{g}=C_{g} V_{g}^{2}=\frac{k_{0} k_{i}}{R+r} V_{g}^{2}, \\
W_{g}=\int_{0}^{T_{2}} \frac{k_{0} k_{i}}{R+r} V_{g}^{2} d_{t},
\end{gathered}
$$

where $\eta_{f}$ is the energy feedback efficiency, $W_{c}$ is the recovery energy, $W_{g}$ is the total input energy, $P_{c}$ is the energy feedback power, $P_{g}$ is the total input power, $U_{c}$ is the energy feedback voltage, $I_{c}$ is the energy feedback current, $C_{g}$ is the electromagnetic damping coefficient, $k_{0}$ is the electromagnetic thrust coefficient, $k_{i}$ is the CEMF coefficient, $R$ is the load resistance, $r$ is the internal resistance of actuator, and $V_{g}$ is the secondary motion speed of the actuator.

The variation of the back electromagnetic force and the energy feedback efficiency of the actuator with the load resistance at different speeds is simulated and analyzed, as shown in Figure 15.

Figure 15 shows that it can be concluded that the back electromagnetic force of the actuator increases with the increase of the moving speed and decreases with the increase of the load resistance. The minimum back electromagnetic force of the actuator is $23 \mathrm{~N}$ at low moving speed and high load resistance, and the maximum back electromagnetic force is $689 \mathrm{~N}$ at high moving speed and low load resistance. The energy feedback efficiency of the actuator increases with the increase of the moving speed and load resistance. The lowest energy feedback efficiency is $10.5 \%$ at low moving speed and load resistance, and the highest efficiency is $27.1 \%$ at high moving speed and load resistance.

\section{Test and Analysis}

6.1. Energy Feedback Characteristic Test of the Actuator. Under the energy feedback mode, the road excitation drives the secondary core of the actuator to make relative motion and cuts the primary internal three-phase coil to generate inductive current. Feeding current charges the supercapacitor through the rectifier and bidirectional DC-DC converter to realize energy recovery. In order to verify the feasibility of energy recovery and the correctness of FEM simulation result of energy feedback efficiency, the prototype of the actuator is improved according to the structure design parameters and the bench test of the new actuator is carried out. The electromagnetic actuator is installed on the suspension test bench. The upper end of the actuator is connected with the upper cross beam that is fixed on the test bed, and the bottom end of the actuator is connected with the bottom cross beam that is connected with the electromagnetic shaking table. The input frequencies of electromagnetic shaking table are $1 \mathrm{~Hz}$ and $2 \mathrm{~Hz}$, and the amplitudes are $10 \mathrm{~mm}$ and $15 \mathrm{~mm}$, respectively. The energy feedback voltage and power are tested. The feeding test is shown in Figure 16. The experimental results are shown in Figures 17 and 18.

Figures 17 and 18 show that the energy feedback power of the electromagnetic actuator increases with the increase of loading excitation frequency and amplitude. According to the energy feedback voltage and power measured by the experiment, the maximum energy feedback efficiency of the 


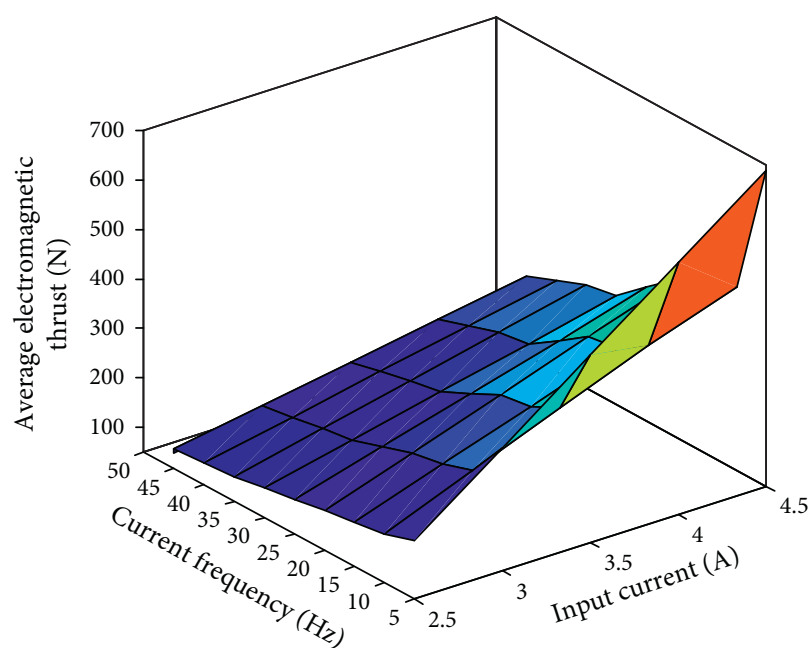

(a)

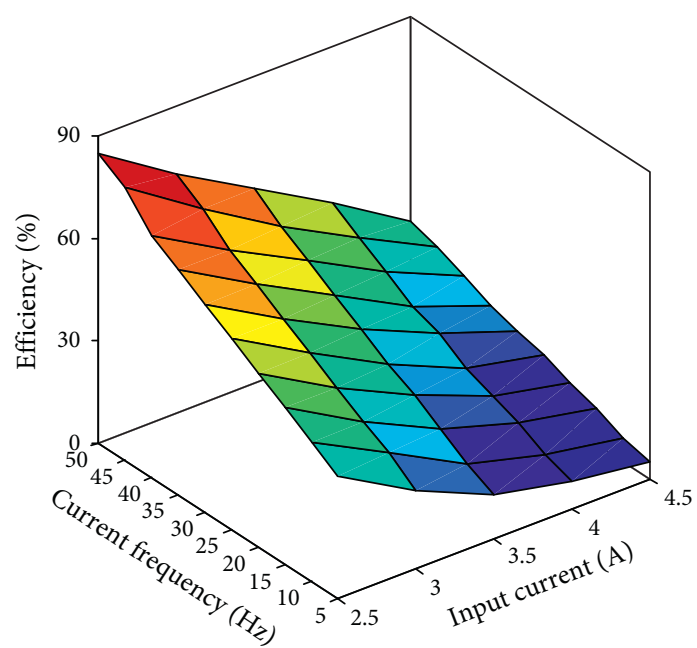

(b)

Figure 14: Distribution of average electromagnetic force and efficiency. (a) Average electromagnetic thrust force. (b) Output efficiency.

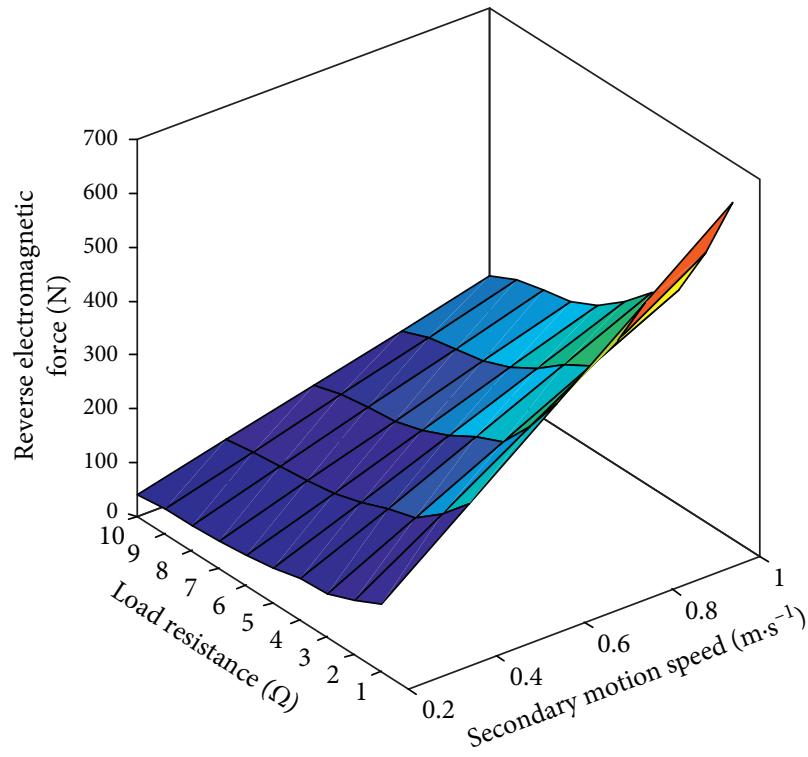

(a)

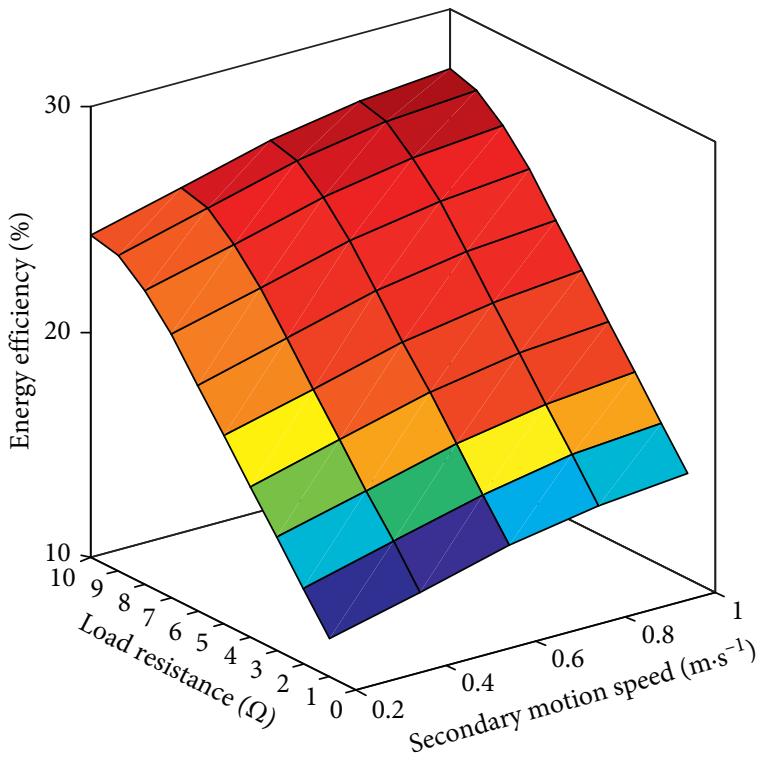

(b)

FIGURE 15: Back electromagnetic force and energy feedback efficiency of actuator. (a) Back electromagnetic force. (b) Energy feedback efficiency.

actuator is $25.6 \%$ at high frequency and amplitude and the minimum is $8.3 \%$ at low frequency and amplitude. According to the FEM analysis, the maximum energy feeding efficiency is $27.1 \%$ and the minimum is $10.5 \%$. These are basically consistent with the experimental results, but there is a certain gap. The main reason is that the resistance in the energy feedback circuit generates energy consumption, and the energy recovery efficiency of the circuit cannot reach $100 \%$. These factors lead to the energy feedback efficiency cannot reach the FEM analysis value.
6.2. Active Characteristic Test of the Actuator. Under the active mode, the electromagnetic actuator outputs electromagnetic thrust force to attenuate the excitation from the road. In order to meet the reduction vibration requirements of suspension, the design structure of the actuator should meet the working performance needed. The active characteristic of the actuator under different currents is tested by the excitation vibration table. In this paper, the peak time is introduced as the response time to reflect the response capability of the actuator [34]. The experimental results are shown in Table 4. 


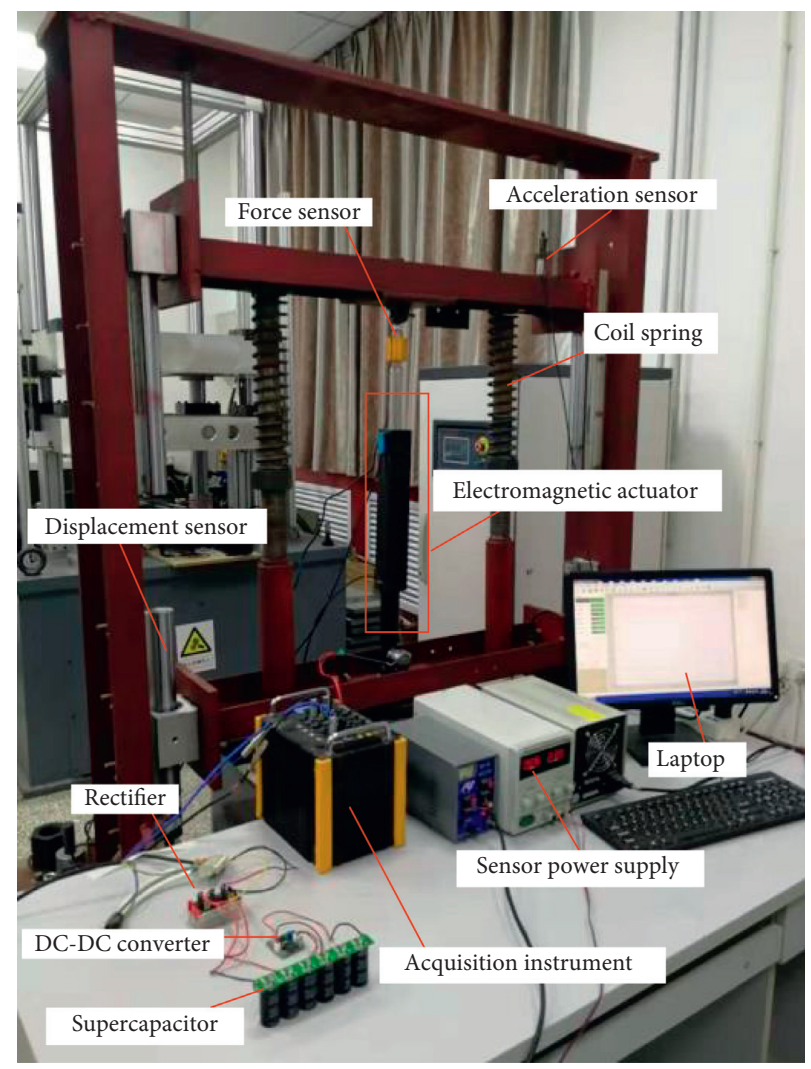

FIGURE 16: Energy feedback characteristic test of the actuator.

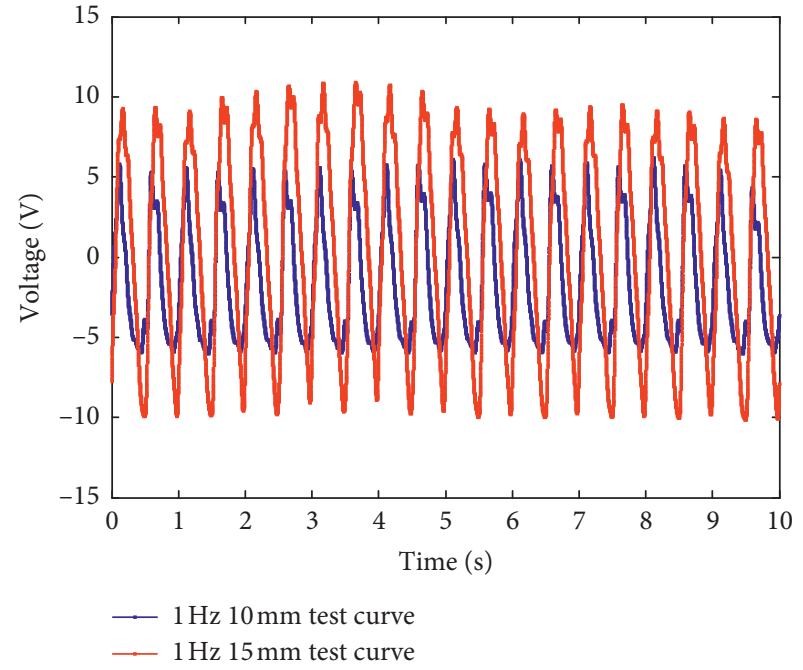

(a)

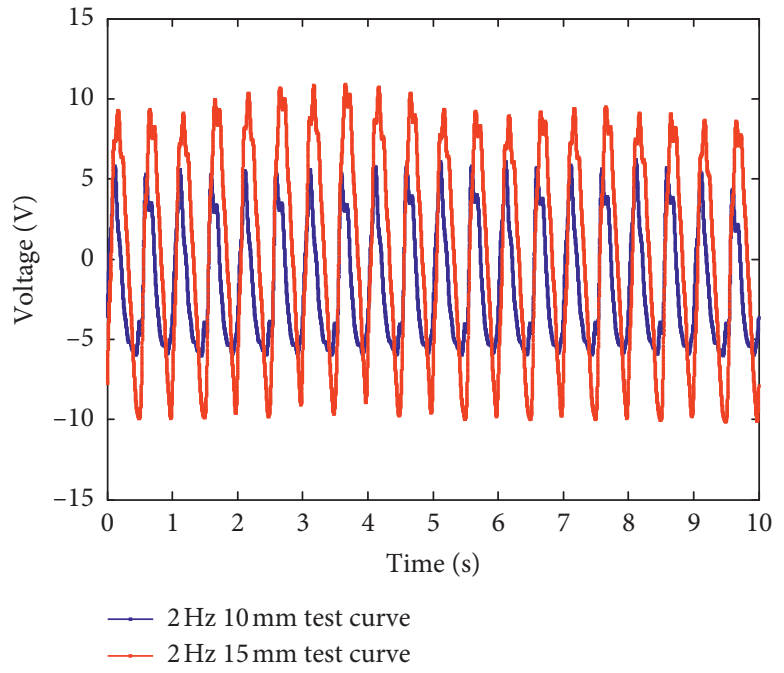

(b)

FigURE 17: Energy feedback voltage of electromagnetic actuator under different excitations.

Table 4 shows that when the load current of the actuator increases, the fluctuation force of the electromagnetic actuator increases, the response time shortens, and the working efficiency decreases. In order to meet the requirement of reduction vibration, with the increase of suspension speed, the load current of electromagnetic actuator should be gradually increased. The highest output efficiency of the actuator is $80.2 \%$ at low current and high frequency, and the lowest output efficiency is $5.9 \%$ at high current and low frequency, which is basically consistent with finite element simulation analysis. 


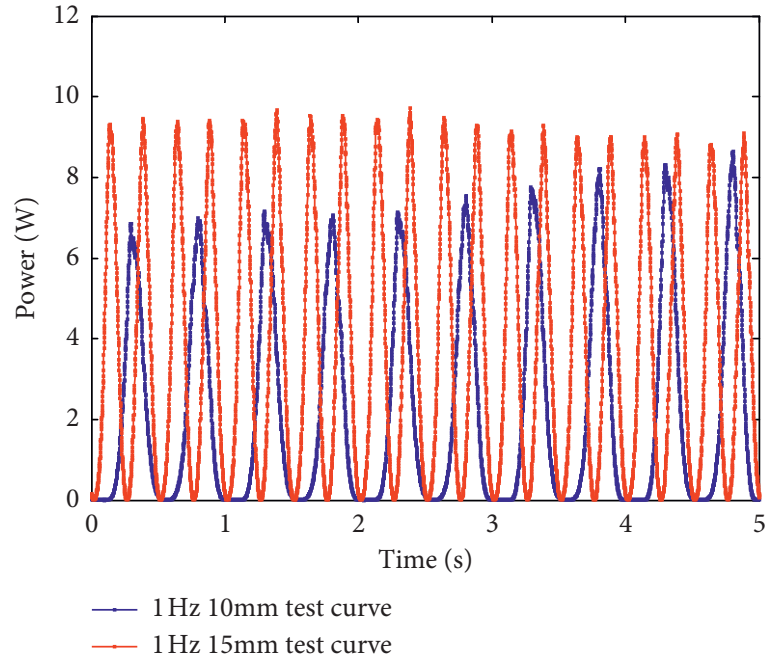

(a)

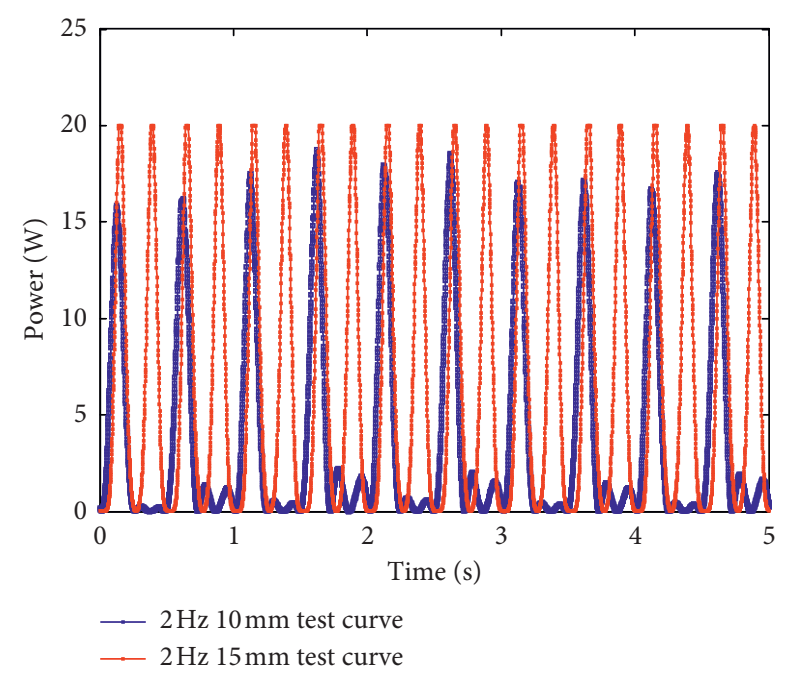

(b)

FIGURE 18: Energy feedback power of electromagnetic actuator under different excitations.

TABle 4: Active characteristic of the actuator under different loads.

\begin{tabular}{lllcccc}
\hline & \multicolumn{2}{c}{ Actuator loads } & \multicolumn{4}{c}{ Actuator outputs } \\
Current $(\mathrm{A})$ & Frequency $(\mathrm{Hz})$ & Speed $\left(\mathrm{m} \cdot \mathrm{s}^{-1}\right)$ & Average thrust $(\mathrm{N})$ & Fluctuate force $(\mathrm{N})$ & Peak time $(\mathrm{ms})$ & Efficiency $(\%)$ \\
\hline 2.5 & 50 & 0.2 & 201 & 21.5 & 35.8 & 80.2 \\
3 & 40 & 0.4 & 367 & 25.6 & 33.4 & 53.4 \\
3.5 & 30 & 0.6 & 516 & 27.4 & 30.7 & 31.6 \\
4 & 20 & 0.8 & 607 & 29.5 & 25.4 & 13.5 \\
4.5 & 10 & 1 & 714 & 31.1 & 21.6 \\
\hline
\end{tabular}

\section{Conclusions}

In order to improve the stability of the actuator designed on an in-wheel motor electric vehicle, the FEM of the actuator is established. On this basis, considering the influences of slot width and edge radian of end tooth on thrust ripple force, structural parameters of the actuator are improved by means of FEM analysis and theoretical calculation. The output accuracy of the actuator is improved, and the influence of the thrust ripple force on the performance of the active suspension is basically eliminated. In addition, the output efficiency and energy feed efficiency of the actuator after reducing thrust ripple are studied. Finally, the correctness of the FEM analysis is verified by the characteristic tests of the actuator under two working modes. The conclusions are as follows:

(1) With the increase of slot width, the thrust fluctuation ratio and total harmonic distortion of the actuator first decrease and then increase. When the slot width is equal to $4.3 \mathrm{~mm}$, the minimum thrust fluctuation ratio is $9.5 \%$ and the total harmonic distortion ratio is $4.2 \%$. With the increase of the edge radian, the cogging force of the actuator first decreases and then increases. When the edge radian is equal to $60^{\circ}$, the minimum cogging fluctuation force is $9.5 \mathrm{~N}$ and electromagnetic fluctuation force is $15.7 \mathrm{~N}$. At the same time, the stability of the actuator is improved obviously with the small sacrifice of average electromagnetic force.

(2) By the analysis of thrust ripple force minimization, the cogging force is reduced to $9.5 \mathrm{~N}$ and the electromagnetic thrust is reduced to $15.7 \mathrm{~N}$. In addition, the cogging force of the actuator accounts for 60.5 percent on the electromagnetic thrust, and it can be concluded that the cogging force is the main source of thrust ripple force. Therefore, it is more effective to restrain the thrust ripple force by reducing the cogging force, which provides a reference for the following similar structure actuators.

(3) The output efficiency of the actuator decreases with the increase of current and increases with the increase of three-phase current frequency. The lowest efficiency is $7.1 \%$ at high current and low current frequency, and the highest efficiency is $87.5 \%$ at low current and high current frequency. The energy feedback efficiency of the actuator increases with the increase of the moving speed and load resistance of the actuator. The lowest energy feedback efficiency is $10.5 \%$ at low moving speed and load resistance, and the highest efficiency is $27.1 \%$ at high moving speed and load resistance.

(4) The prototype of the actuator is improved according to the structure design parameters, and the bench 
test of the new actuator is carried out. The test results show that under the suspension system energyfeeding mode, the energy feedback efficiency of the actuator reaches $25.6 \%$. Under the active mode of the actuator, when the suspension speed increases, in order to meet the demand of reduction vibration, the input current should be increased gradually and its response ability becomes faster and efficiency decreases. The maximum output efficiency is $80.2 \%$, which is basically consistent with the results of FEM analysis and provides a reference for the whole vehicle equipment of the actuator.

\section{Data Availability}

The data used to support the findings of this study are available from the corresponding author upon request.

\section{Conflicts of Interest}

The authors declare that they have no conflicts of interest.

\section{Acknowledgments}

This work was supported by the National Natural Science Foundation of China (Grant no. 51775426); Shaanxi Provincial Key Research and Development Plan (Grant no. 2018ZDCXL-GY-05-04); and Research and Development of Applied Technology in Beilin District of Xi'an City in 2019 (Grant no. GX1928).

\section{References}

[1] S. Murata and Satoshi, "Innovation by in-wheel-motor drive unit," Vehicle System Dynamics, vol. 50, no. 6, pp. 807-830, 2012.

[2] Y.-y. Wang, Y.-n. Li, W. Sun, and L. Zheng, "Effect of the unbalanced vertical force of a switched reluctance motor on the stability and the comfort of an in-wheel motor electric vehicle," Proceedings of the Institution of Mechanical Engineers, Part D: Journal of Automobile Engineering, vol. 229, no. 12, pp. 1569-1584, 2015.

[3] K. Nam, H. Fujimoto, and Y. Hori, "Lateral stability control of in-wheel-motor-driven electric vehicles based on sideslip angle estimation using lateral tire force sensors," IEEE Transactions on Vehicular Technology, vol. 61, no. 5, pp. 1972-1985, 2012.

[4] S.-A. Chen, J.-C. Wang, M. Yao, and Y.-B. Kim, "Improved optimal sliding mode control for a non-linear vehicle active suspension system," Journal of Sound and Vibration, vol. 395, no. 9, pp. 1-25, 2017.

[5] K. Huang, Y. Fan, and Y. Zhang, "Design of model predictive controller for electromagnetic active suspension," Journal of Shanghai Jiaotong University, vol. 44, no. 11, pp. 1619-1624, 2010.

[6] Y. Fan, Y. Zhang, G. Zhang et al., "Technical synthesis of vehicle electromagnetic suspension," Automotive Engineering, vol. 34, no. 7, pp. 569-574, 2012.

[7] M. Cui, L. Geng, and Z. Wu, "Random modeling and control of nonlinear active suspension," Mathematical Problems in Engineering, vol. 2017, Article ID 4045796, 8 pages, 2017.
[8] F.-R. Kou, D.-D. Wei, and L. Tian, "Multimode coordination control of a hybrid active suspension," Shock and Vibration, vol. 2018, Article ID 6378023, 16 pages, 2018.

[9] M. Montazeri-Gh and O. Kavianipour, "Investigation of the active electromagnetic suspension system considering hybrid control strategy," Proceedings of the Institution of Mechanical Engineers, Part C: Journal of Mechanical Engineering Science, vol. 228, no. 10, pp. 1658-1669, 2014.

[10] H. E. Tseng and D. Hrovat, "State of the art survey: active and semi-active suspension control," Vehicle System Dynamics, vol. 53, no. 7, pp. 1034-1062, 2015.

[11] D. Wang, D. Zhao, M. Gong et al., "Nonlinear predictive sliding mode control for active suspension system," Shock and Vibration, vol. 2018, Article ID 8194305, 10 pages, 2018.

[12] K. Singal and R. Ajamani, "Zero-energy active suspension system for automobiles with adaptive sky-hook damping," Journal of Vibrationand Acoustics, vol. 135, no. 1, Article ID 011011, 2013.

[13] J. Zhang, L. Zhang, T. Luo et al., "Design and experiment research of compound electromagnetic actuator of vehicle suspensions," Journal of Academy of Armored Force Engineering, vol. 29, no. 1, pp. 30-35, 2015.

[14] R. Wang, J. Xie, Y. E. Qing et al., "Modeling and experimental study of active suspension with linear motor," Automotive Engineering, vol. 38, no. 4, pp. 495-499, 2016.

[15] M. Montazeri-Gh, M. Soleymani, and S. Hashemi, "Impact of traffic conditions on the active suspension energy regeneration in hybrid electric vehicles," IEEE Transactions on Industrial Electronics, vol. 60, no. 10, pp. 4546-4553, 2013.

[16] Z. Li, L. Zuo, J. Kuang et al., "Energy-harvesting shock absorber with a mechanical motion rectifier," Smart Materials and Structures, vol. 22, no. 2, Article ID 025008, 2013.

[17] Z. Li, L. Zuo, G. Luhrs, L. Lin, and Y.-x. Qin, "Electromagnetic energy-harvesting shock absorbers: design, modeling, and road tests," IEEE Transactions on Vehicular Technology, vol. 62, no. 3, pp. 1065-1074, 2013.

[18] M. Cao, W. Liu, and Yu Fan, "Development on electromotor actuator for active suspension of vehicle," Chinese Journal of Mechanical Engineering, vol. 44, no. 11, pp. 224-228, 2008.

[19] E. Babak, K. M. Behrad, and G. Farid, "A novel eddy current damper: theory and experiment," Journal of Physics D: Applied Physics, vol. 42, pp. 1-6, 2009.

[20] Z. Deng and F. Lai, "Electromagnetic linear actuator for vehicle active suspension," Journal of Mechanical Engineering, vol. 47, no. 14, pp. 121-128, 2011.

[21] J. Lin, K. W. E. Cheng, Z. Zhang, N. C. Cheung, X. Xue, and T. W. Ng, "Active suspension system based on linear switched reluctance actuator and control schemes," IEEE Transactions on Vehicular Technology, vol. 62, no. 2, pp. 562-572, 2013.

[22] C. Ma, X. Yang, J. Zhang et al., "Thrust spectrum analysis of linear motor for motion stability," Journal of Xi'an Jiaotong University, vol. 49, no. 8, pp. 45-51, 2015.

[23] B. Yu, "Research on transverse flux permanent magnet linear motor with cylindrical staggered teeth," Harbin University of Technology, 2016.

[24] Y. I. Klimenko, D. V. Batishchev, A. V. Pavlenko, and V. P. Grinchenkov, "Design of a linear electromechanical actuator with an active vehicle suspension system," Russian Electrical Engineering, vol. 86, no. 10, pp. 588-593, 2015.

[25] R. Guo, H. Yu, Y. Wang, H. Chen, X. Liu, and T. Xia, "Detent force minimization of an improved linear permanent magnet synchronous motor," International Journal of Applied Electromagnetics and Mechanics, vol. 58, no. 4, pp. 513-529, 2018. 
[26] J. Wang, W. Wang, and K. Atallah, "A linear permanentmagnet motor for active vehicle suspension," IEEE Transactions on Vehicular Technology, vol. 60, no. 1, pp. 55-63, 2011.

[27] L. Zheng, Design and Analysis of Five-phase Fault-Tolerant Permanent Magnet Cylindrical Linear Motor for Electromagnetic Suspension, Jiangsu University, Zhenjiang, China, 2017.

[28] Y. Tang, Design and Research of Cylindrical Linear Permanent Magnet Motor for Flight Simulator, Huazhong University of Science and Technology, Wuhan, China, 2015.

[29] J. Wang, G. W. Jewell, and D. Howe, "A general framework for the analysis and design of tubular linear permanent magnet machines," IEEE Transactions on Magnetics, vol. 35, no. 3, pp. 1986-2000, 1999.

[30] J. Wang and D. Howe, "Design optimization of radially magnetized, iron-cored, tubular permanent-magnet machines and drive systems," IEEE Transactions on Magnetics, vol. 40, no. 5, pp. 3262-3277, 2004.

[31] X. Wang, Y. Yang, T. Ding et al., "Research on cogging torque reduction method of solid rotor permanent magnet synchronous motor based on pole arc coefficient selection," Chinese Journal of Electrical Engineering, vol. 25, no. 15, pp. 146-149, 2005.

[32] Q. Zhang, B. Liang, R. Huang et al., "Effect of slot width on cogging torque of fractional slot concentrated winding permanent magnet motor," Motor and Control Application, vol. 42, no. 15, pp. 1-5, 2015.

[33] L. Wang, Research on Key Control Technology and Application of Modern Linear Motor, Zhejiang University, Zhenjiang, China, 2012.

[34] W. Hao, "Analysis and compensation of nonlinear inductance and thrust fluctuation of permanent magnet linear synchronous motor," Journal of Tsinghua University (Natural Science Edition), vol. 12, pp. 1968-1973, 2010. 